\title{
Aprimoramento Conceitual e Uso de Demonstrações Matemáticas: Um Estudo de Caso Sobre a Geometria Dinâmica e as Pesquisas de Campo com Ambientes Computacionais de Ensino
}

\author{
Conceptual Enhancement and the use of Mathematical Proofs: a Case Study on Dy- \\ namic Geometry and Field Researches using Computational Teaching Systems \\ Emília B. FERREIRA \\ CEDERJ-Universidade Federal Flu- \\ minense - UFF \\ ebarraferreira@yahoo.com.br \\ Adriana B. SOARES \\ Universidade Salgado de Oliveira \\ Universidade do Estado do Rio de \\ Janeiro (UNIVERSO, UERJ) \\ adriana.benevides@pq.cnpq.br \\ Cabral LIMA \\ Universidade Federal do Rio de Janei- \\ ro - UFRJ (PPGI-DCC/NCE-IM) \\ cabrallima@ufrj.br
}

\begin{abstract}
Resumo Esta publicação mostra uma pesquisa original sobre implicações conceituais decorrentes de pesquisas de campo que usam ambientes computacionais de ensino. Os resultados de um estudo de caso confirmaram a hipótese de que a participação de professores em pesquisas de campo desta natureza pode servir de auto-estímulo para: i) dar continuidade à formação; ii) aprimorar as conceitualizações e os futuros processos de ensino e aprendizagem. $O$ uso de demonstrações matemáticas foi particularmente analisado e essa abordagem embasou os propósitos sedimentais de identificar, compreender e codificar as conceitualizações, dadas as habilidades docentes em fazer demonstrações. Os resultados também mostraram que as conceitualizações adquiridas em pesquisas de campos são conservadas e se traduzem posteriormente numa docência mais segura, ladeada por uma maior habilidade e um uso mais consciente de ambientes computacionais de ensino.
\end{abstract}

Palavras-Chave: práticas docentes, geometria dinâmica, ambientes computacionais de ensino, demonstrações matemáticas, pesquisas de campo.

\begin{abstract}
This paper shows an original research on conceptual implications from field researches that use computational teaching systems. The results obtained from a case study established the hypothesis that the involvement of teachers in this kind of field researches is a self-stimulation to : i) continue training, ii) enhance the conceptualizations and later teaching-learning processes. The use of mathematical proofs was particularly analyzed in this research and this approach supported the foremost purposes of identify, understand and codify the conceptualizations, known the teaching dexterities with mathematical proofs. The results also have shown that the conceptualizations acquired in field researches are preserved and subsequently converted into both a safer teaching and a better skill in using computational teaching systems.
\end{abstract}

Keywords: teaching practices, dynamic geometry, computational teaching systems, mathematical proofs, field researches.

Recebido: 08 de Agosto de 2012 / Aceito: 12 Dezembro de 2012

DOI: $10.5753 /$ RBIE.2012.20.03.13 


\section{Introdução}

O objetivo desta publicação é o de mostrar que conceitualizações advindas de participação em pesquisa de campo, em que são utilizados ambientes computacionais, se aprimoram ao longo do tempo e se traduzem posteriormente numa melhor prática docente e numa busca por formações profissionais suplementares. Essa pesquisa baseia-se num estudo de caso que envolveu professores de matemática que já haviam participado de uma pesquisa de campo anterior (utilizando ambientes computacionais para o ensino da geometria) e a abordagem nela adotada permitiu e embasou os propósitos sedimentais de identificar, compreender e codificar as conceitualizações. A principal hipótese confirmada é a de que as conceitualizações adquiridas em pesquisas de campos são conservadas e se traduzem posteriormente numa prática docente mais segura, ladeada por uma maior habilidade e uso mais consciente de ambientes computacionais de ensino. $\mathrm{O}$ uso de demonstrações matemáticas no ensino da geometria foi particularmente avaliado neste estudo de caso, cujo instrumento descritivo-interpretativo requereu uma análise fundamentalmente qualitativa.

Comunicação, tecnologia e educação se constituem num tripé fundamental para a formação do homem do século XXI. A tecnologia cria condições para que a comunicação social se insira cada vez mais nos espaços educacionais, o que favorece a socialização do saber, notadamente através de suas dinâmicas de distribuição de informações [16]. Nesse contexto, o surgimento da informática como instrumento de informação, comunicação e interação foi um novo paradigma pois ela não consiste apenas num recurso suplementar de melhoria pedagógica, mas, adicionalmente, num recurso capaz de propiciar a inclusão social, a distribuição da informação através de uma construção coletiva do conhecimento ([31], [35]) e a possibilidade de levar o aluno à cidadania[30]. Os ambientes computacionais da mesma forma que vieram favorecer a comunicação também transformaram as exigências de qualificação e de formação, modificando, consequentemente, o nível funcional e estrutural da escola. As mudanças educacionais passaram a não consistir apenas da disponibilização de suportes tecnológicos potencializados, mas, primordialmente, da filosofia e da concepção das ações educacionais associadas. $\mathrm{O}$ conhecimento advém do questionamento, da dúvida, de conjecturas a serem testadas[32], da necessidade constante de busca por novas alternativas, do debate $\mathrm{e}$, notadamente, da interação[10].

O professor é, neste contexto, um catalisador de ações educacionais que, entre outras coisas, deve conhecer os detalhes e as vicissitudes (e estar preparado para enfrentálos) das mudanças provocadas pelo uso de ambientes computacionais nos processos de ensino e aprendizagem. Todavia, tal preparação frequentemente perpassa a sua formação inicial. As constantes e céleres transformações tecnológicas exigem irrefutavelmente uma formação continuada do professor: preparar o professor é condição sine qua non para o sucesso dos ambientes computacionais em sala de aula.

A comunidade de informática na educação sabe que atualmente não há mais dúvidas quanto ao potencial benéfico do uso dos ambientes computacionais nos processos de ensino e aprendizagem. A preocupação tem se voltado ultimamente mais para a forma de utilização desses ambientes, que deve, entre outras coisas, obedecer a critérios de objetividade e efetiva aplicabilidade. Ou seja, o enfoque vem se deslocando progressivamente da questão de se a máquina é ou não benéfica aos processos de ensino e aprendizagem para a questão de como a máquina pode ser mais favoravelmente utilizada nesses processos. Particularmente, as questões relativas à utilização de tecnologias computacionais para o ensino da matemática já são bastante conhecidas por terem sido objeto de várias pesquisas, notadamente após a profusão de diversos sistemas computacionais dedicados a muitas subáreas da matemática.

Existe ainda alguma distância entre ter acesso aos ambientes computacionais e efetivamente utilizá-los nos processos de ensino e aprendizagem. $\mathrm{O}$ acesso não significa instantaneamente o uso e, portanto, esforços vêm sendo perpetrados por diversos atores do contexto educacional visando atenuar essa distância. No âmbito da geometria dinâmica, o projeto Europeu Intergeo ([28], [29]) representa um recente esforço nessa direção. $\mathrm{O}$ cerne desse projeto é precisamente o de tratar com o problema de como projetar, compartilhar e propiciar o correto uso de diversas ferramentas tecnológicas em processos de ensino e aprendizagem da geometria dinâmica.

Algumas pesquisas de campo na matemática têm também buscado contribuir para essa temática direcionando seus esforços à formação inicial e continuada de professores com aplicação de ambientes computacionais nos contexto da sala de aula ([4], [13], [26], [27]). A pesquisa de campo com docentes em início de carreira exposta em [26], por exemplo, analisou as contribuições plausíveis dos ambientes computacionais para um curso de licenciatura em matemática. Nessa pesquisa, as concepções sobre ambientes computacionais, expressas pelos diversos participantes, foram captadas também através de entrevistas semi-estruturadas, que foram objeto de uma análise descritiva-interpretativa, analogamente ao desenvolvido no 
presente estudo de caso. A contribuição principal dessa pesquisa foi a de que o uso de ambientes computacionais na formação inicial pode impactar positivamente a futura atuação dos professores de matemática.

Richit e Maltempi [4] também refletiram sobre diversas possibilidades propiciadas pelos ambientes computacionais no processo de formação inicial docente e desenvolveram um estudo em torno da questão de "como trabalhar com projetos em geometria analítica usando software de geometria dinâmica, visando favorecer a formação de futuros professores de matemática". Essa pesquisa, de caráter essencialmente qualitativo, examinou estudantes do primeiro ano de licenciatura em matemática dentro de ambientes de aprendizagem nos quais eram desenvolvidos projetos temáticos em geometria analítica (usando um sistema computacional de geometria dinâmica). Os métodos dessa pesquisa incluíam: $a$ ) gravações em áudio e vídeo das sessões de trabalho; $b$ ) aplicação de questionários semi-estruturados buscando evidenciar concepções dos licenciandos sobre o papel das tecnologias na formação e na prática docente em matemática; $c$ ) entrevistas individuais. Em consonância com os resultados obtidos esse trabalho sugere que a experiência de trabalho com projetos e tecnologias integrados favorece a formação inicial do aluno, pois o futuro professor tem a possibilidade de apropriar-se de conceitualizações específicas, pedagógicas e tecnológicas de forma articulada e complementar.

A pesquisa descrita em [9] aborda a formação continuada de professores de matemática e investiga se o uso de ambientes computacionais dedicados à geometria pode contribuir (através da apropriação de habilidades e metodologias) para um uso mais consciente de demonstrações em sala de aula. Para atingir esse objetivo foi efetuada uma pesquisa de campo (que é a pesquisa de campo referência da presente pesquisa) através de uma metodologia qualitativa, cujos instrumentos foram: $a$ ) questionários de sondagem (inicial e final); $b$ ) produção de material escrito pelos participantes; $c$ ) observação do comportamento e das deliberações dos professores durante as atividades realizadas e nas discussões de textos. A partir dos resultados encontrados, foi sugerido que o uso de sistemas computacionais dedicados à geometria se constitui numa alternativa eficiente para o processo de formação de professores.

O questionamento basilar da presente pesquisa está intrinsecamente associado ao seguinte questionamento: a participação de professores em pesquisas de campo, que envolvam ambientes computacionais de ensino, repercute e aprimora as conceitualizações adquiridas, a formação continuada, e os processos de ensino e aprendizagem? Assim sendo, os oito professores que participaram da pesquisa referência também participaram do estudo de caso associado ao presente estudo. Isto permitiu tanto coletar dados significativos para tentar responder ao questionamento supracitado, como também permitiu uma análise substanciada sobre o uso de demonstrações matemáticas em sala de aula.

\section{Método}

Considerado o objetivo descritivo-interpretativo da presente pesquisa, optou-se por uma abordagem qualitativa de caráter interpretativo. A opção por essa abordagem norteia-se também por algumas asserções estabelecidas por alguns teóricos([18], [19]). Bryan [7], por exemplo, executou uma importante pesquisa qualitativa para avaliar a credibilidade, a riqueza e o valor do uso de sistemas computacionais dedicados à geometria dinâmica no aprendizado, utilizando uma abordagem descritivainterpretativa de questionários e entrevistas que foram obtidos durante processos de ensino-aprendizagem em sala de aula. Alves-Mazzotti [2] também afirma que é através de pesquisas qualitativas que é plausível encontrar a possibilidade de estudar questões difíceis de quantificar, tais como sentimentos, motivações, concepções, e atitudes. Ponte [17] estabelece que num estudo interpretativo pretende-se primordialmente conhecer a realidade tal como ela é vista pelos atores que nela intervêm diretamente.

Sob esse prisma, a abordagem descritiva-interpretativa adotada nesta pesquisa permite e embasa os propósitos sedimentares de codificar, identificar e compreender conceitualizações e práticas de professores quando eles se posicionam sobre suas experiências e suas perspectivas tanto em relação à utilização de ambientes computacionais quanto ao uso de demonstrações matemáticas em sala de aula. A fim de enriquecer e embasar algumas ponderações, determinadas informações da presente pesquisa foram também quantificadas. As entrevistas realizadas e a respectiva análise dos dados foram efetuadas tanto sob a égide dos resultados encontrados na pesquisa de campo referência quanto em consonância com teorias basilares dessa temática ([11], [19]).

\subsection{Participantes}

Participaram desta pesquisa oito professores de matemática que são aqui identificados ficticiamente como: Aldo, Ana, Áurea, Cora, Eli, Gui, Lila e Rosa. Os nomes fictícios usados para preservar a identidade dos mesmos mantêm a mesma representação utilizada na pesquisa de campo referência, executada quatro anos antes. Esses professores exercem suas funções em diferentes escolas públicas e/ou particulares do município de Angra dos Reis, Rio de Janeiro, no Ensino Fundamental (E. F.) ou no Ensino Médio (E. M.). À exceção de dois (um com 
formação em administração e outro com apenas nível médio), todos os professores têm graduação em licenciatura em matemática. O tempo de experiência deles no magistério varia de 05 a 35 anos.

\subsection{Instrumentos}

O instrumento utilizado foi a entrevista e os dados analisados foram coletados durante os encontros programados entre professores e entrevistador. Optou-se pela entrevista semi-estruturada a fim de se poder garantir a possibilidade de adaptações e também de permitir o registro de informações não previstas sobre experiências dos participantes [18]. A entrevista era constituída de duas partes. A primeira parte se direcionava à obtenção de dados sociodemográficos do entrevistado, ou seja, na metodologia utilizada foram consideradas questões que permitiram a identificação e a análise de cenários da vida dos entrevistados. Os dados então solicitados incluíam informações sobre: $a$ ) Idade; $b$ ) Tempo de magistério; $c$ ) Escolas em que trabalha atualmente; $d$ ) Carga horária semanal de trabalho; $e$ ) Trabalhar ou não a geometria em suas aulas; f) Utilizar demonstrações em suas explicações de sala de aula; $g$ ) Cursos feitos ou em andamento nos últimos anos.

A segunda parte da entrevista compreendia questões buscando captar conceitos e sentimentos do professor a respeito da geometria, do uso das demonstrações em sala de aula e da utilização de ambientes computacionais (particularmente dos ambientes computacionais de geometria) na prática docente. As perguntas constantes dessa parte são: a) Por ocasião dos trabalhos realizados na pesquisa de campo referência, você considerou o uso de programas de geometria dinâmica como uma ferramenta importante para o ensino e a aprendizagem da geometria? O que você pensa a esse respeito, hoje? b) Após haver participado na pesquisa de campo em questão, você utilizou ou utiliza algum desses recursos tecnológicos em suas aulas? c) Em caso positivo, onde? Quando? Como? d) Independente de sua predisposição à utilização desses recursos, que fatores contribuiriam para que você os incluísse em suas estratégias de ensino? e) E quais fatores o levariam a não utilizálos? f) Em termos de logística escolar, que estrutura você considera necessária para uma prática que favoreça o uso dos ambientes computacionais? Em que escolas de sua cidade de trabalho você encontraria esse ambiente? $g$ ) Que outras considerações você gostaria de registrar?

\subsection{Ambientes de geometria dinâmica}

Conceitualmente, ambientes de geometria dinâmica são sistemas computacionais que proporcionam construções gráficas e manipulações espaciais de sólidos e curvas geométricos. Mais recentemente, a geometria dinâmi- ca tem sido designada como geometria interativa [36], notadamente em ambientes dedicados a dispositivos móveis[32]. Esses ambientes normalmente dispõem de régua e compasso virtuais e de vários outros recursos que são também comuns em outros ambientes de matemática. Há, no entanto, alguns recursos inerentes aos ambientes de geometria dinâmica que os diferem dos outros sistemas computacionais dedicados à matemática. Dentre esses recursos típicos dos ambientes de geometria dinâmica, o "arrastar" é, seguramente, o mais significativo. Selecionando com o mouse um ponto de um objeto construído num ambiente, arrasta-se o objeto fazendo aparecer uma coleção de desenhos em movimento cujas propriedades formadoras (os chamados “invariantes”) são mantidas.

No ambiente de geometria dinâmica Geogebra [22], por exemplo, pode-se construir um triângulo ABC (Figura 1) e, em seguida, suas bissetrizes $\mathrm{AD}, \mathrm{BE}$ e CF (traçadas com linhas pontilhadas). O ponto de interseção dessas bissetrizes (o incentro) é identificado como o ponto $\mathrm{G}$, e os segmentos GH, GI e GJ representam as distâncias do ponto $\mathrm{G}$ aos lados $\mathrm{AB}, \mathrm{BC}$ e $\mathrm{CA}$ do triângulo $\mathrm{ABC}$. Uma propriedade desse ponto $\mathrm{G}$ é que ele equidista dos lados do triângulo e, assim sendo, se constitui no centro da circunferência inscrita no triângulo. Esta circunferência inscrita $p$ tem os segmentos GH, GI e GJ como raios. Se arrastarmos com o mouse essa construção geométrica de uma posição para outra da tela, algumas propriedades permanecerão invariantes durante todo o processo do arraste.

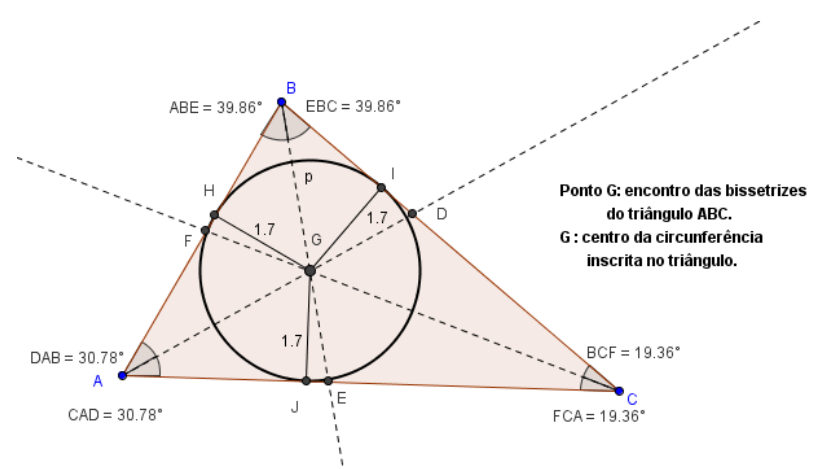

Figura 1: O "arrastar" e as conjecturas invariantes de uma circunferência inscrita no triângulo $\mathrm{ABC}$

Com efeito, arrastando-se ABC por um de seus vértices, inúmeras e diferentes visualizações de configurações do triângulo vão surgindo dinamicamente na tela. Embora possam variar a forma e as medidas do triângulo $\mathrm{ABC}$ durante todo o processo do arrastar, algumas conjecturas continuam invariantes, tais como as semirretas bissetrizes, o baricentro e a circunferência inscrita $p$ com centro em G e raio GH. A Figura 2 mostra o triângulo $\mathrm{ABC}$ na configuração de um triângulo isósceles aonde podem ser ob- 
servadas essas conjecturas invariantes.

Através de manipulações geométricas dessa natureza, com exploração espacial através da ferramenta arrastar, um aluno pode constatar e, portanto, se certificar, sobre algumas propriedades geométricas antes abordadas limitadamente de forma teórica. A possibilidade de visualização e manipulação de objetos geométricos que guardam as conjecturas invariantes possibilitam, frequentemente, um aprimoramento tanto da habilidade de visualizações de propriedades geométricas quanto da compreensão efetiva e definitiva de conceitos geométricos importantes [8].

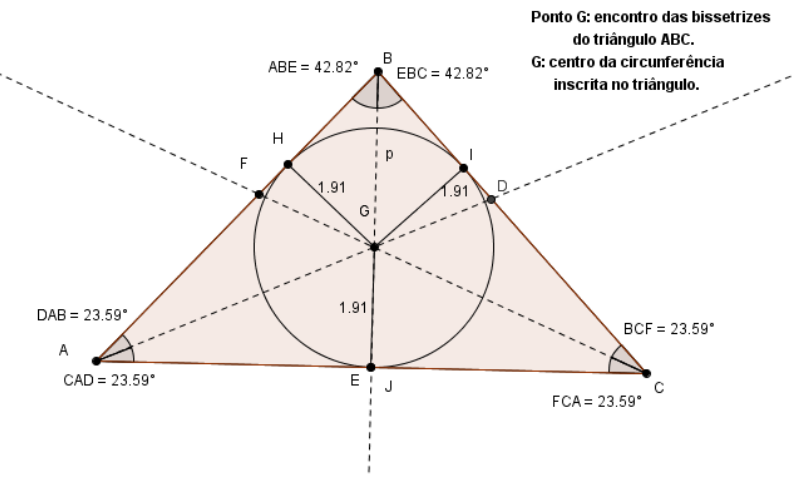

Figura 2: $\mathrm{O}$ triangulo isósceles $\mathrm{ABC}$ e as conjecturas preservadas

Em [3] encontram-se catalogados vários esquemas sobre o arrastar de objetos geométricos e também é demonstrada a invariabilidade de algumas propriedades envolvidas, mostrando que quando uma conjectura é verificada enquanto um diagrama está sendo arrastado, então essa conjectura será sempre verdadeira para toda a visualização possível. Essa pesquisa também mostrou, através de estudos de casos, que o uso do arrastar pode auxiliar substancialmente a consolidar os conhecimentos de estudantes em geometria.

Vários sistemas computacionais dedicados ao ensino da geometria têm sido desenvolvidos e aperfeiçoados nestes últimos anos. Além do Geogebra, outros ambientes bastante utilizados tem sido o Tabulae [25], o Cabri Geometre [6] e o Geometer's Sketchpad [24]. Outro importante fator tem sido a forma de como representações externas podem corroborar no desenvolvimento desses sistemas computacionais, notadamente para facilitar a compreensão de conhecimentos complexos ([33], [34], [37]). Embora alguns professores tenham a praxe de escolher um ambiente como padrão e, eventualmente, associálo a algumas outras ferramentas tecnológicas (para potencializar os exemplos e exercícios), existem ambientes que, por características peculiares, são mais apropriados do que outros para determinados exemplos e/ou exercí- cios de geometria. No entanto, lançar mão de vários ambientes para uma mesma turma de alunos demanda certo "sacrifício" tanto por parte do professor quanto por parte dos alunos. Isto ocorre porque, normalmente, cada ambiente possui sua própria formatação e sua maneira de manipular objetos geométricos e, frequentemente, aborda conceitos de uma forma quase singular pois os expõe, através de seus processos de visualização, via os recursos que lhe são inerentes.

O uso de um ambiente suplementar em sala de aula certamente acarreta a necessidade de um aprendizado adicional sobre como manipulá-lo corretamente, o que pode desviar ou retardar o aprender da geometria propriamente dita. Visando justamente minimizar esse problema, Fest [1] propõe um esquema para integração de vários desses ambientes e mostra a aplicabilidade desse esquema em processos de ensino e aprendizagem. A interação se faz graças à execução síncrona e não-intrusiva de algoritmos automáticos e/ou semi-automáticos que permeiam os códigos dos ambientes.

\subsection{Procedimentos}

Cada professor, previamente informado sobre a proposta teórica e as práticas adotadas para o estudo de caso associado à presente pesquisa, foi entrevistado individualmente em datas acordadas antecipadamente. Cada entrevista foi efetuada na residência do entrevistado com duração de 120 a 180 minutos. Foram gastos cerca de quatro meses para que o processo de todas as entrevistas fosse completamente consolidado. Uma singularidade interessante nesses procedimentos foi a aquiescência animada dos participantes, possivelmente por se tratar de um estudo de caso que evocava uma agradável participação deles numa pesquisa de campo anterior. O natural retrospecto, durante a entrevista, à participação do entrevistado na pesquisa de campo referência certamente facilitou o desenrolar do procedimento como um todo, além de relembrar vários conceitos geométricos e propriedades de ambientes computacionais que haviam sido abordados durante a pesquisa de campo referência. Os diálogos da livre interação entre o professor e o entrevistador foram gravados e, posteriormente, transcritos e arquivados. A idéia subjacente foi a de possibilitar o uso desse material por futuros pesquisadores da área e, adicionalmente, de disponibilizar uma base de dados para estudos correlacionados no porvir.

Concluído o processo das entrevistas, procedeu-se subsequentemente ao tratamento das informações coletadas. Inicialmente, a partir de cada entrevista, foram avaliadas e transcritas as informações relevantes. A análise dos dados coletados envolveu a seguinte sequência de passos: i) Leituras particulares e globais das respostas e colocações dos professores para uma visão ampla e genérica do 
quadro; ii) Tratamento dos dados sociodemográficos (colhidos durante a primeira parte da entrevista) através de sua organização e categorização, a partir de critérios relativamente flexíveis e previamente definidos, em acordo com as idéias basilares da presente pesquisa; iii) Análise dos dados relativos às concepções e às expectativas dos professores quanto ao ensino da geometria, quanto à necessidade do uso de demonstrações em sala de aula e quanto à contribuição dos ambientes de geometria dinâmica para a eficiência do aprendizado (colhidos durante a segunda parte da entrevista); As expectativas puderam ser delineadas a partir da leitura das colocações dos entrevistados e das descrições elencadas sobre as condições desejáveis para o sucesso dos processos de ensinoaprendizagem; iv) Análise comparativa dos dados colhidos para o presente estudo com os dados correlatos que foram obtidos na pesquisa de campo referência e em consonância com as teorias pertinentes; A ideia era a de auscultar quais ações indicavam aprimoramentos em conceitualizacões e/ou nos processos de ensino e aprendizagem, alguns destes decorrentes de auto-estímulos à formação continuada.

\section{Análises dos resultados}

São apresentados nessa seção os dados coletados nas entrevistas, as interpretações sobre esses dados e suas conexões com algumas teorias relacionadas às temáticas discutidas.

\subsection{Resultados sociodemográficos}

Dos oito professores participantes apenas dois não têm formação em licenciatura matemática: a professora Áurea é formada em Administração (mas com pósgraduação em matemática) e a professora Cora possui formação pedagógica de nível médio. Por outro lado, quase todos possuem uma experiência no magistério superior a dez anos: apenas o professor Gui exerce essa função no período de 05 a 10 anos.

\begin{tabular}{c|c|l|l}
\hline $\begin{array}{c}\text { Nome, } \\
\text { Idade }\end{array}$ & $\begin{array}{c}\text { Magistério } \\
\text { (anos) }\end{array}$ & $\begin{array}{l}\text { Ensina Geome- } \\
\text { tria, Usa } \\
\text { Demonstração }\end{array}$ & $\begin{array}{c}\text { Usa } \\
\text { ambi- } \\
\text { ente }\end{array}$ \\
\hline Aldo, 45 & $\begin{array}{c}10<\text { tempo<20 } \\
\text { Sim, Às vezes }\end{array}$ & $\begin{array}{l}\text { Às } \\
\text { vezes }\end{array}$ \\
\hline Ana, 51 & tempo>20 & Sim, Sim & Não \\
\hline Áurea, 53 & $10<$ tempo<20 & Sim, Sim & Não \\
\hline Cora, 58 & tempo>20 & Sim, Não & Não \\
\hline Eli, 52 & tempo $>20$ & Sim, Sim & Não \\
\hline Gui, 36 & tempo>20 & Não, Às vezes & $\begin{array}{l}\text { Às } \\
\text { vezes }\end{array}$ \\
\hline
\end{tabular}

\begin{tabular}{l|l|l|l}
\hline Lila, 42 & tempo>20 & Sim, Sim & Não \\
\hline Rosa, 44 & tempo>20 & Sim, Sim & $\begin{array}{l}\text { Às } \\
\text { vezes }\end{array}$ \\
\hline
\end{tabular}

Tabela 1: Resultados sobre os professores entrevistados

No que concerne o uso de sistemas computacionais como um instrumento de auxílio às aulas, apenas três professores entrevistados informaram já os terem utilizado efetivamente em sala de aula. Em termos de fazer demonstrações matemáticas em sala de aula durante a explanação da matéria, a maioria dos professores entrevistados informou que habitualmente faz demonstrações como forma de convencimento, embora alguns professores tenham admitido que as façam mas não em grande escala (vide Tabela 1). Apenas a professora Cora não as utiliza, o que poderia eventualmente ser entendido como certa insegurança, possivelmente ocasionada pelo o fato de ela possuir apenas uma formação de nível médio.

A Tabela 2 mostra os dados relativos à carga horária semanal de trabalho dos professores entrevistados e como tal carga se distribui pelas várias unidades escolares nas quais eles atuam. Uma breve análise desses dados mostra que os professores Aldo, Gui e Rosa possuem uma carga horária semanal excessiva, uma característica que vem se tornando cada vez mais natural devida à necessidade quase imperativa do professor brasileiro ter que buscar a melhoria de seu salário final ministrando aulas em diversas unidades escolares.

\begin{tabular}{|c|c|c|}
\hline Nome & Escola: Nível (Séries) & Carga Horária \\
\hline Aldo & $\begin{array}{l}\text { Particularl: } \mathrm{EF}\left(7^{\circ} 8^{\circ}\right. \\
\left.9^{\circ}\right), \mathrm{EM}\left(1^{\circ} 2^{\circ} 3^{\circ}\right) \\
\text { Particular2: } \mathrm{EF}\left(8^{\circ}\right. \\
\left.9^{\circ}\right), \mathrm{EM}\left(1^{\circ} 2^{\circ}\right) \\
\text { Municipal: } \operatorname{EJA}\left(6^{\circ} \text { ao }\right. \\
\left.9^{\circ}\right) \\
\text { Estadual: } \mathrm{EM}\left(1^{\circ}\right)\end{array}$ & $45 \mathrm{~h} / \mathrm{semana}$ \\
\hline Ana & $\begin{array}{l}\text { Particularl: } \operatorname{EF}\left(8^{\circ} 9^{\circ}\right) \\
\text { Particular2: } \operatorname{EM}\left(1^{\circ}\right)\end{array}$ & $12 \mathrm{~h} / \mathrm{semana}$ \\
\hline Áurea & $\begin{array}{l}\text { Particular: } \operatorname{EF}\left(8^{\circ} 9^{\circ}\right) \\
\operatorname{EM}\left(1^{\circ} 2^{\circ} 3^{\circ}\right)\end{array}$ & $15 \mathrm{~h} / \mathrm{semana}$ \\
\hline Cora & Particular: EF(6 $\left.6^{\circ} 7^{\circ}\right)$ & $12 \mathrm{~h} / \mathrm{semana}$ \\
\hline Eli & $\mathrm{ni}$ & $\mathrm{ni}$ \\
\hline Gui & $\begin{array}{l}\text { Particular: } \operatorname{EF}\left(6^{\circ} 7^{\circ}\right) \\
\operatorname{EM}\left(1^{\circ} 2^{\circ}\right) \\
\text { Federal: } \operatorname{EM}\left(1^{\circ} 2^{\circ}\right) \\
\text { Estadual: } \operatorname{EM}\left(1^{\circ} 2^{\circ}\right. \\
\left.3^{\circ}\right)\end{array}$ & $45 \mathrm{~h} / \mathrm{semana}$ \\
\hline Lila & Estadual: $\operatorname{EF}\left(6^{\circ} 7^{\circ} 8^{\circ}\right)$ & $28 \mathrm{~h} / \mathrm{semana}$ \\
\hline Rosa & $\begin{array}{l}\text { Particularl: } \operatorname{EM}\left(1^{\circ} 2^{\circ}\right. \\
\left.3^{\circ}\right) \\
\text { Particular2: } \mathrm{EM}\left(1^{\circ} 2^{\circ}\right. \\
\left.3^{\circ}\right) \\
\text { Municipal: } \operatorname{EJA}\left(6^{\circ} \text { ao }\right. \\
\left.9^{\circ}\right)\end{array}$ & $45 \mathrm{~h} /$ semana \\
\hline
\end{tabular}


Tabela 2:Dados de trabalho dos professores entrevistados. $\mathrm{EF}=$ Ensino Fundamental; EM= Ensino Médio; EJA= Educação Jovens e Adultos; $\mathrm{ni}=$ não informou.

\subsection{Conceitualizações acerca dos ambientes}

Todos os professores entrevistados confirmaram conceitualizações positivas sobre os sistemas computacionais dedicados ao ensino de geometria. Eles ressaltaram que através desses ambientes as conceitualizações matemáticas podem ser compreendidas mais espontaneamente e de forma peremptória. Todos estavam também de acordo que a contribuição capital desses ambientes está baseada na possibilidade (que eles frequentemente oferecem) de um aluno poder construir o objeto geométrico desejado e poder visualizá-lo detalhadamente sob múltiplos ângulos. Esse detalhamento habitualmente é resultado de operações espaciais com o objeto geométrico, tais como rotações, projeções, junções, expansões ou deslocamentos simétricos. Essa possibilidade corrobora para que as conceitualizações matemáticas correlacionadas venham a ser mais bem absorvidas e registradas pelo aluno que, em geral, o faz de forma espontânea e comumente definitiva.

Foi consenso geral entre os professores que a propriedade do "arrastar" é uma ferramenta extremamente importante na edificação de raciocínios significativos para a construção e a manipulação de objetos geométricos. Eles assinalaram que, através do "arrastar", os alunos podem entender as leis matemáticas de formação e de caracterização comportamental de objetos geométricos, o que, adicionalmente, ajuda a desenvolver no aluno o gosto pelas demonstrações. Existe, portanto, certa indissociabilidade entre as demonstrações geométricas e as construções (e subsequentes manipulações) de objetos geométricos. Um aluno que em sua formação usa ambientes computacionais que facilitam as conjecturas espaciais de objetos geométricos pode, futuramente, ser um professor com uma natural habilidade de usar demonstrações em sala de aula.

Um objeto construído pode ter sua percepção final melhor elaborada e melhor compreendida por um aluno se desenhos que geram instâncias desses objetos, no decorrer de um intervalo de tempo, podem ser manipuladas e percebidas paulatinamente e de acordo com a "velocidade" do aluno. A integração desses movimentos figurais no objeto final aumenta a percepção geométrica e ajuda a compreensão de conceitos matemáticos e espaciais do objeto [8]. Isto resulta também em facilidade para edificar raciocínios lógicos e compreender demonstrações matemáticas.

Alguns posicionamentos dos professores entrevistados aqui transcritos podem refletir de forma natural essas concepções acerca dos ambientes computacionais de ensino: "Através deles as propriedades das figuras po- dem ser observadas claramente, pois com o "arrastar" elas se mantêm, desde que a figura seja construida através de suas características básicas" (Prof. Aldo); "Eu achava, mas hoje tenho certeza, que a informática no ensino-aprendizagem da matemática ajuda muito o aluno a construir seu conhecimento. Com os ambientes de geometria dinâmica, o aluno fica com uma noção melhor de como as propriedades dos objetos acontecem. A essência desses ambientes é a construção do conhecimento a partir de várias informações dadas" (Prof. Ana); "No momento de trabalhar as demonstrações, a sua característica de manter as propriedades ao arrastar torna mais claro o caminho a seguir. Eu fico até triste por não dominar a informática para poder tirar mais proveito $e$ utilizar essa ferramenta nas minhas aulas. Se para nós, naquela ocasião, foi tão interessante e proveitoso, imagine como seria para essa garotada que vive essa realidade do computador. Eu diria que esse é um recurso indispensável nos dias atuais" (Prof. Eli).

A solução de problemas de geometria requer, fortemente, conjunturas visuais e deslocamentos de figuras, ainda que esses deslocamentos possam vir a serem feitos de forma exclusivamente mental. Assim sendo, poder construir e arrastar objetos geométricos numa tela de computador é, sem dúvida, um suporte extremamente bem vindo ao raciocínio e ao aprendizado da geometria. Diversos trabalhos de pesquisa direcionados ao estudo das aplicações de novas tecnologias ressaltam que os ambientes de geometria dinâmica podem ser um forte aliado na resolução de problemas enfrentados no ensino da geometria ([5], [10], [12], [20], [21], [23]).

Alguns aspectos positivos relacionados ao uso de ambientes de geometria dinâmica em sala de aula relatados pelos professores foram: "O fundamental, no trabalho com um ambiente, é a interação que ocorre. O professor vai interagir melhor com seus alunos e os alunos entre si, também. Ficar, em aula, só falando é vago para o aluno. Nesses ambientes, o aluno interage, participa e se interessa" (Prof. Gui); "Esses ambientes são importantes por desenvolverem o raciocínio do aluno, por criarem condição para que ele possa tirar conclusões sobre o objeto estudado e por contribuirem para o desenvolvimento da própria linguagem do aluno ao exigir que ele escreva sobre o que está vendo acontecer" (Prof. Lila); "O uso desses ambientes deveria ser obrigatório no Ensino Fundamental, pois é nessa fase que o aluno está começando a adquirir e forma a base para a geometria abstrata. A denominação da geometria, nessa fase, deveria ser geometria dinâmica" (Prof. Rosa).

\subsection{Conceitualizações acerca das demonstra- ções}

Os professores participantes, em consonância com as 
teorias da área, ressaltaram unanimemente que as demonstrações são muito importantes para o ensino da geometria. Eles entendem que fazer demonstrações favorece a compreensão das relações entre os objetos geométricos, dos teoremas e das fórmulas. Com efeito, demonstrar contribui, em última instância, para um desenvolvimento sedimentado do raciocínio lógico-dedutivo no aluno. Contudo, há de se notar que, com respeito à aplicação de demonstrações em sala de aula, o procedimento de alguns desses professores não coaduna diretamente com essa perspectiva. Enquanto alguns a usam sistematicamente, outros a empregam esporadicamente (e a professora Cora simplesmente não faz demonstrações em sala de aula).

Os professores concordam com a idéia de que a utilização de ambientes de geometria dinâmica impulsiona o desenvolvimento de um trabalho ao mesmo tempo motivador e consistente com as demonstrações, como ser observado: "As demonstrações são importantes na compreensão das fórmulas. No caso de esquecimento das mesmas, o aluno tem condição de reavivá-las pelo processo já entendido de sua demonstração. O sistema de geometria dinâmica pode ajudar muito, pois permite que o aluno olhe a figura e busque o que está acontecendo com suas propriedades. Visualiza e faz articulações usando raciocínio dedutivo. Apesar de tudo, eu as utilizo muito pouco em minhas aulas, pelo falta de tempo e pelo desinteresse dos alunos" (Prof. Aldo); "As demonstrações são muito válidas para que o aluno perceba o conhecimento como algo não pronto, mas sim construido ao longo da historia. Que uma idéia puxa a outra, que por trás de uma fórmula, existe um encadeamento de conceitos, de propriedades. É algo dinâmico, à medida que você vai avançando, vai arrastando conteúdos, vai evoluindo para outros conhecimentos. As demonstrações sempre fizeram e fazem parte de minhas aulas" (Prof. Ana).

As demonstrações podem ser definidas como sendo cadeias finitas [15], logicamente articuladas, de formas declarativas no contexto de um sistema formal determinado, possuindo vocabulário próprio e regras sintáticas bem determinadas. As opiniões dos professores Aldo e Ana, acima transcritas, expressam precisamente essa correta conceituação acerca das demonstrações. Para a professora Eli, por exemplo, as demonstrações possuem importantes funcionalidades e, como tal, devem fazer parte integrante e efetiva dos processos de ensino-aprendizagem da geometria: "Através delas, os teoremas, as relações, as fórmulas são melhores entendidas e fixadas. As coisas têm outro sentido. Com os programas de geometria dinâmica fica bem viável trabalhá-las. Eu sempre usei demonstrações em minhas aulas" (Prof. Eli).

Ainda sob esse prisma de análise, a essência da mate- mática reside na construção de métodos, instrumentos, estratégias e nas definições conceituais necessários para a resolução de problemas [14]. Como as demonstrações incorporam justamente esses elementos, elas deveriam ser o foco primário do interesse matemático, para vencer os desafios que essa matéria impõe, notadamente no que concerne o uso das demonstrações. Evitar ou simplesmente não fazer demonstrações em sala de aula pode ser interpretado pelos alunos como uma atemorizada insegurança do professor. O professor Gui, por exemplo, admite que a insegurança que ele possui ao fazer demonstrações em sala de aula deve estar intrinsecamente relacionada às possíveis deficiências ocorridas em sua formação inicial: "Na minha formação, não tive quase nada de demonstrações. Confesso que tenho muita dificuldade em usá-las. Quando preciso, fico confuso e sempre me pergunto por onde começar. Por isso quase não as uso em meu cotidiano de sala de aula. Com a experiência no trabalho que fizemos com aquele programa usado, acho que pode ficar mais fácil entender como fazer as demonstrações" (Prof. Gui).

Sob uma conceitualização mais rigorosa, os pesquisadores da informática aplicada ao ensino sabem que debates dessa natureza, notadamente os que buscam compreender a origem de problemas recorrentes em sala de aula, são capitais para o desenvolvimento da sociedade como um todo. Como nós, cientistas, sabemos, é através de trabalhos de pesquisadores e educadores que muito se tem conquistado em termos de melhoria do nível educacionaltecnológico da sociedade, em várias áreas do saber. A matemática, por exemplo, sempre tem sido reconhecida como uma disciplina difícil de ser estudada, complexa para ser aprendida e implexa de ser ministrada. Relatos de trabalhos e pesquisas dessa área têm sido fortemente incentivados porque podem revelar parâmetros importantes que poderão ser utilizados para a melhoria dos processos de ensino-aprendizagem como um todo. Em particular, no que concernem as demonstrações matemáticas, elas possuem um papel fundamental nesse contexto, especialmente pela característica cogente do uso do raciocínio lógico, seja ele dedutivo ou indutivo. Com efeito, as demonstrações requerem o pensar e, concomitantemente, também ensinam a raciocinar.

Saber fazer demonstrações matemáticas, portanto, não é uma habilidade que se adquire com facilidade e/ou celeridade. Trata-se de uma competência que se edifica paulatinamente ao longo de uma formação persistida. Portanto, por conseqüência direta, pode-se estabelecer que a competência de um professor está, indubitavelmente e de forma intrínseca, ligada à qualidade e perenidade de sua formação. Alunos em geral não aprendem a fazer demonstrações na maioria dos níveis acadêmicos a que freqüentam, nem em cursos universitários, nem depois 
Aprimoramento Conceitual e Uso de Demonstrações Matemáticas: Um Estudo de Caso Sobre a Geometria Dinâmica e as Pesquisas de Campo com Ambientes Computacionais de Ensino

que se formam e nem depois que se tornam professores. Há, infortunadamente, um potencial ciclo vicioso: o aluno não vivencia em sala de aula os processos adequados às demonstrações matemáticas e quando mais tarde torna-se professor, ou evita de fazer demonstrações para seus alunos ou as faz, mas de forma imprópria e/ou insegura, o que não permite aos seus alunos vivenciar os processos adequados às demonstrações matemáticas.

Fazendo ou esquivando-se das demonstrações matemáticas em sala de aula, os professores participantes do presente estudo de caso possuem, no entanto, plena consciência do papel essencial que as demonstrações têm para a matemática e, particularmente, para o ensino da geometria. Eles enalteceram a grande contribuição que os ambientes computacionais dinâmicos podem dar para a inclusão natural de demonstrações nos processos de ensinoaprendizagem da geometria. Essa relação entre o aprender a demonstrar e o uso de ambientes de geometria dinâmica pode provocar, adicionalmente, uma reestruturação na maneira de raciocinar e um subseqüente desenvolvimento de novas competências cognitivas que são fundamentais para os processos de ensino e aprendizagem.

\section{Práticas Docentes}

Como ilustra a Tabela 1, apenas três dos oito professores entrevistados utilizam ocasionalmente tecnologias computacionais em suas aulas. Segundo esses professores, isso não significa um total desinteresse por essa prática, mas sim a extrema dificuldade de executá-la adequadamente. Esta dificuldade está mormente baseada no fato de quase não existir laboratório de informática (na acepção pragmática do termo) disponível nas escolas em que trabalham, embora, paradoxalmente, algumas escolas usem vários computadores para a gestão administrativa.

As afirmações da professora Cora, por exemplo, além de refletirem sobremaneira essa situação, também sugerem implicações positivas de sua experiência obtida quando participou da pesquisa de campo referência: “ $A$ participação na pesquisa anterior me ajudou muito na geometria. Usando um programa, passei a compreender melhor certos conceitos e também as demonstrações. Fiquei com melhor visão das coisas. Mesmo sem usar o computador, aplico em minhas aulas o que aprendi e elas estão bem melhores. Quero participar de outros encontros" (Prof. Cora).

\begin{tabular}{c|l|c}
\hline Nome & Nova Formação: Nível & Situação \\
\hline Aldo & $\begin{array}{l}\text { Novas Tecnologias no } \\
\text { Ensino da Matemática: } \\
\text { Pós-Graduação }\end{array}$ & Interrompido \\
\hline Ana & $\begin{array}{l}\text { Novas Tecnologias no } \\
\text { Ensino da Matemática: } \\
\text { Pós-Graduação }\end{array}$ & Em curso \\
\hline Áurea & Não & Não \\
\hline
\end{tabular}

\begin{tabular}{c|l|c}
\hline Cora & \multicolumn{1}{|c|}{ Não } & Não \\
\hline Eli & \multicolumn{1}{|c}{$\begin{array}{c}\text { Gestão Escolar: } \\
\text { Pós-Graduação }\end{array}$} & Concluído \\
\hline Gui & $\begin{array}{l}\text { Licenciatura Física: } \\
\text { Graduação }\end{array}$ & Interrompido \\
\hline Lila & $\begin{array}{l}\text { Fundamentos de Geome- } \\
\text { tria: } \\
\text { Aperfeiçoamento } \\
\text { Funções: } \\
\text { Aperfeiçoamento }\end{array}$ & Concluído \\
\hline Rosa & $\begin{array}{l}\text { Informática na Educa- } \\
\text { ção: } \\
\text { Aperfeiçoamento }\end{array}$ & Interrompido \\
\hline
\end{tabular}

Tabela 3:Busca dos professores por novas formações.

A Tabela 3 ilustra a participação dos professores em cursos suplementares à formação desde a participação deles na pesquisa referência com ambientes computacionais de ensino. Pode-se depreender dessa tabela, portanto, que nos últimos quatro anos existem, medianamente, iniciativas desses professores na busca por novos conhecimentos em formações suplementares, ainda que as professoras Áurea e Cora não tenham demonstrado nenhuma iniciativa promissora nessa direção. Os professores Aldo e Rosa buscaram cursos de aperfeiçoamento sem, entretanto, conseguir concluí-los. A professora Lila, apesar de ter se esforçado e iniciado dois cursos concomitantes, conseguiu concluir apenas um deles. O professor Gui, a despeito de ser formado em matemática, buscou uma nova formação na área de física, contudo, a pouca disponibilidade de tempo para se dedicar aos estudos o impediu de continuar nesta formação. A professora Ana está cursando uma pós-graduação na área de educação matemática. Esses professores admitiram a triste constatação de que os cursos foram abandonados devido à grande carga de trabalho à qual estão submetidos.

Nesse escopo, as considerações das professoras Ana e de Áurea, transcritas a seguir, revelam que as respectivas participações na pesquisa de campo referência as habilitaram a refletir melhor acerca de sua formação e as motivou para buscar novos aperfeiçoamentos profissionais: " $A$ participação na pesquisa anterior serviu mais para minha formação do que para aplicação prática. Fiquei motivada, busquei outros cursos e os conhecimentos adquiridos sobre os ambientes de geometria dinâmica estão me ajudando muito no curso de novas metodologias que faço" (Prof. Ana); "Nas atividades do estudo, pudemos ver prazerosamente como o ambiente podia contribuir com nosso trabalho sobre o desenvolvimento de demonstrações. Por outro lado, serviu para mostrar que nós não estávamos tão próximos das verdades das demonstrações. Com isso, fui a busca de aperfeiçoar alguns conceitos que, ao participar daquele grupo, vi que não estavam tão bem elaborados por mim. Isso foi muito importante" (Prof. Áurea).

Observa-se prontamente que a participação em pes- 
quisas de campo em que são utilizados ambientes computacionais de ensino se mostra como um auto-estímulo para o professor buscar seu aperfeiçoamento, ainda que, por outro lado, exista um grande entrave que encontra-se, infelizmente, na grande carga de trabalho. Com efeito, uma grande carga de trabalho aliada à necessidade de deslocamentos entre diversas unidades de ensino (através de um sistema de transporte nem sempre muito eficaz) implica numa demanda assaz significativa de tempo, o que diminui substancialmente a disponibilidade para se buscar formações suplementares. Na realidade, a melhoria dessa situação só ocorre se houver um maior investimento na educação, tanto em contextos locais quanto no contexto nacional, um fator que, a despeito da forma relegada com a qual tem sido tratado, é a condição sine qua non para um país poder efetivamente se desenvolver.

\subsection{O uso de ambientes computacionais e os processos de ensino e aprendizagem: fa- tores facilitadores e inibidores}

De acordo com os relatos dos professores entrevistados sobre os fatores que podem permitir, ou provocar, a utilização de ferramentas computacionais nos processos de ensino-aprendizagem da matemática, vale à pena destacar: i) Tempo disponível para preparar e planejar atividades; ii) A formação continuada dos professores, incluindo participação em cursos; iii) Haver cobrança e acompanhamento por parte das direções de escola, das coordenações; iv) Carga horária maior da disciplina para que esses trabalhos tenham espaço para serem desenvolvidos; v) A mentalidade da equipe gestora da escola e conseqüente engajamento nesse projeto; vi) A existência de laboratório na escola; vii) Número reduzido de alunos para trabalhar, para que o professor possa acompanhá-los; viii) Pessoal de apoio ao professor: coordenador de área, assistente técnico.

Quanto aos fatores que inibem, ou mesmo impedem, o uso de ambientes computacionais em sala de aula, os professores entrevistados relataram mais incisivamente: $i$ ) O desinteresse dos alunos; ii) Falta de compromisso do professor, inclusive no planejamento dos trabalhos; iii) A não cobrança da direção ao professor; iv) Falta de tempo do professor; $v$ ) O despreparo do professor para esse tipo de trabalho; vi) Falta de profissionais que auxiliem o professor nessa tarefa: técnicos, coordenador de informática etc.

Os relatos dos professores entrevistados apontam nitidamente para o fato de que o uso efetivo e eficiente de tecnologias computacionais na educação não depende apenas da vontade ou da iniciativa do professor e/ou do aluno. Há, indubitavelmente, necessidade de um processo gestor atuante que organize, coordene, introduza, mante- nha e estimule atividades letivas com o uso dos ambientes computacionais. Este uso deve refletir a naturalidade, a singeleza e a eficácia das tecnologias adotadas, evidenciando os efeitos positivos que esse uso traz tanto para o processo de aprendizagem per si quanto para uma adaptação mais célere à dinamicidade tecnológica atual. Isso requer, portanto, uma percepção inovadora do contexto educacional e uma conjunção de pensamentos e de ações entre os integrantes da unidade escolar responsáveis pela prática pedagógica.

Os ambientes computacionais devem ser considerados como um meio e não como um fim e, por este motivo, devem ser integrados a todos os processos que ocorrem na escola. Novos ambientes computacionais envolvendo a computação ubíqua, a embarcabilidade digital (uso de celulares, tablets etc. como destino de material pedagógico e meio de interação educacional) e a computação em nuvem (cloud computing) irão certamente abrolhar mais incisivamente no cenário da informática aplicada ao ensino e, por consequência direta, provocar a necessidade do repensar em novas metodologias que se adéquem ao dinamismo tecnológico do porvir. Assim sendo, é fundamental que surja uma cultura tecnológica em todos os ambientes de aprendizagem, aonde não apenas professores e alunos sejam os beneficiados, mas todos os membros deles pertencentes, sem que alguma exceção seja percebida. Desta forma, o professor de uma escola deve ser percebido como um nó de uma ampla rede conectando diversos atores do cenário educacional. Para o sucesso de todo o processo educacional da escola essa rede deve ser acionada de forma contínua e expressiva, através da ativação de todos os seus nós (o professor, o aluno, o gestor, os técnicos etc.) e dos arcos que ligam esses nós (as famílias, o projeto pedagógico, a infra-estrutura etc.).

\section{Conclusões}

Neste artigo avaliou-se impactos conceituais e de formação continuada gerados à partir de participações em pesquisas de campo que usam ambientes computacionais de ensino. A ideia basilar foi a de aferir o quanto a participação de professores em pesquisas de campo dessa natureza pode refletir, de forma ativa, na formação desses professores, num aprimoramento conceitual e na melhoria dos processos de ensino e aprendizagem. A meta foi, portanto, a de verificar até que ponto os novos conhecimentos podem se integrar às conceitualizações anteriormente obtidas para, de forma conjunta, se traduzirem em num aprimoramento efetivo dos processos de ensino e aprendizagem em sala de aula. Sob essa perspectiva foi examinada, durante todo o estudo, qual é a importância do uso de demonstrações em sala de aula e sua indissociabilidade da qualidade da formação continuada e dos 
processos de ensino e aprendizagem da geometria.

$\mathrm{O}$ instrumento aplicado para o estudo de caso associado foi a entrevista semi-estruturada. As análises dessas entrevistas mostraram que as conceitualizações obtidas pelos professores entrevistados, com respeito à importância das demonstrações e da contribuição dos ambientes computacionais para o ensino da geometria dinâmica (que foram desenvolvidos por ocasião da pesquisa de campo referência), se aprimoraram. Os depoimentos dos professores permitem seguramente sugerir que a participação na pesquisa de campo referência não só ampliou seus conhecimentos e conceitualizacões geométricas, como também aprimorou suas posturas e práticas docentes.

No interstício de tempo entre a pesquisa de campo referência e o estudo agora descrito, a procura e a frequência por cursos suplementares à formação foi um fator observado e que refletiu e concretizou o anseio desses professores por crescer profissionalmente. Paralelamente a esse anseio constatou-se também o reconhecimento irrefutável da necessidade da inserção dos ambientes computacionais nos processos de ensino-aprendizagem.

Outro dado relevante é o fato de que a utilização de ambientes de geometria dinâmica por esses professores, em suas práticas pedagógicas, ainda não ocorre como poderia ter sido esperado. Tal fato justifica-se, especialmente, pela raridade do componente indispensável para isso: o laboratório de informática. Isto não significa absolutamente a falta de computadores nas escolas (públicas ou privadas), mas a frequente ausência de um ambiente efetivamente apropriado para o desenrolar de processos de ensino-aprendizagem baseados em ambientes computacionais de ensino.

Pela análise dos depoimentos dos professores é possível inferir que a participação em pesquisas de campo, que envolvam tecnologias computacionais, traz a percepção da necessidade de continuar a ter uma formação de qualidade. Essa percepção tende a se transformar numa procura futura por novos cursos e é elemento propulsor para a busca por novos conhecimentos tecnológicos, como mostrou o estudo de caso. Adicionalmente, pode-se também coligir que essa participação funciona como um ponto de partida para efetivas e duradouras mudanças em seus conceitos e práticas educativas adotados nos processos de ensino e aprendizagem.

Como metas de trabalho futuras sugere-se realizar treinamentos pedagógicos e capacitações dos professores para que sejam colocadas em prática não somente o uso das novas tecnologias como também a utilização de demonstrações para o desenvolvimento do raciocínio dos alunos. Ainda que os professores tenham se sensibilizado e verificado a importância do uso de uma ferramenta tecnológica que facilita a visualização e o aprendizado da geometria e estejam conscientes que as demonstrações matemáticas auxiliam nas estratégias de raciocínio na edificação do conhecimento, é preciso que isso seja posto em prática de forma a tornar-se uma atividade exercida com assiduidade.

O estudo realizado sinaliza caminhos para a formação continuada de professores envolvendo tecnologias computacionais, não somente via "tomada de consciência", mas também por meio de cursos ou capacitações. Entende-se que um projeto que vise exercitar o uso das novas tecnologias e a prática de demonstrações propicie o enriquecimento da formação específica, pedagógica e tecnológica de seus participantes e de seus alunos, criando possibilidades que a) favoreçam a exposição, a reflexão e o debate dos professores participantes sobre aspectos relacionados a sua prática docente; b) permitam ao professor, através da experimentação e da investigação em determinado ambiente computacional, a reconstrução e ampliação de seus conhecimentos, renovando, assim, conteúdos, metodologias e perspectivas de sua própria formação e atuação.

No contexto de uma formação profissional, o uso de ambientes computacionais, mesmo na área de ciências exatas como a matemática, tem provocado mudanças significativas nas abordagens de conceitos e problemas e, consequentemente, nas práticas docentes. Em particular, o uso de ambientes computacionais dedicados ao ensino da geometria tem se constituído, nos últimos anos, numa significante e eficiente ferramenta de aceleração do processo de formação de professores dessa área. Isto deriva, notadamente, do fato de que nesses ambientes podem ser contemplados tanto os aspectos conceituais matemáticos quanto os aspectos inerentemente didáticos da geometria.

$\mathrm{O}$ uso de ambientes computacionais permite, adicionalmente, facilitar e agilizar a aprendizagem do próprio conhecimento geométrico ao mesmo tempo em que disponibiliza, para os processos de ensino e aprendizagem, novas ferramentas que foram especialmente concebidas para estimular uma edificação peremptória do conhecimento, através do estímulo à construção de raciocínios coerentes e adequados. Com efeito, essa edificação do conhecimento tende a acontecer de forma natural, e geralmente definitiva, precisamente por causa do favorecimento ao desenvolvimento do raciocínio lógico ao invés de memorizações de fórmulas e/ou ações similares.

Pode também ser depreendido desta pesquisa que a utilização adequada de ambientes computacionais e ferramentas tecnológicas pode otimizar substancialmente $o$ uso de demonstrações em sala de aula. Particularmente em geometria isso ocorre porque os ambientes dinâmicos contemplam tanto os aspectos conceituais quanto os aspectos didáticos da geometria e, portanto, favorecem o uso de demonstrações, que, por sua vez, ajudam à com- 
preensão peremptória do conhecimento matemático no geral e da geometria no particular.

Pode-se, portanto, estabelecer que as implicações conceituais adquiridas em pesquisas de campo exercem um papel fundamental no auto-estímulo pela busca de uma formação continuada e que esteja em consonância com os avanços educacionais e tecnológicos. Particularmente na área da matemática, o uso dos ambientes computacionais dedicados associado a diversas ferramentas tecnológicas vai ao encontro do anseio universal do professor por incutir em seu aluno a busca por um sólido conhecimento, o que é frequentemente obtido através da edificação natural de raciocínios lógicos que permeia, de forma apropriada, o uso de processos de demonstrações em sala de aula.

\section{Referências}

[1] A. Fest. Adding Intelligent Assessment: a Java Framework for Integrating Dynamic Mathematical Software Components into Interactive Learning Activities. ZDM Mathematics Education. 43: 413-423, 2011.

[2] A. J. Alves-Mazzotti. O Método nas Ciências Naturais e Sociais. Em: A. J. Alves-Mazzotti, F. Gewandsznajder (eds.) O Método nas Ciências Naturais e Sociais: Pesquisa Quantitativa e Qualitativa. Editora Pioneira, Parte II. São Paulo, 2003.

[3] A. Restrepo. L'instrumentation du déplacement dans un environnement de géométrie dynamique En: I. Bloch, F. Conne (eds.). Nouvelles perspectives en didactique des mathématiques. La Pensée Sauvage. A(2), 2007.

[4] A. Richit, M. V. Maltempi. Desafios e Possibilidades do Trabalho com Projetos e com Tecnologias na Licenciatura em Matemática. ZETETIKÉ Unicamp. 18(33): 14-40, 2010.

[5] A. S. Brito, M. C. Costa Explorando o Teorema de Pitágoras com Geogebra. Educação Matemática em Revista. 14(26): 26-32, 2009.

[6] C. Laborde, J. M. Laborde. Problem Solving in Geometry: from Microworlds to Intelligent Computer Environments. In: J. Pontes et al. (eds.). Mathematical Problem Solving and New Information Technologies. NATO ASI series F, Springer-Verlag 89: 177-192, 1991.

[7] D. Bryan. The Impact of Dynamic Geometry software on Learning. Teaching Mathematics and its Applications. 20(4): 157-169, 2001.

[8] C. Lima, A. B. Soares, G. Alves. Geometric Visualization: How to Acquire It Using Dynamic Geometry Systems? In: Proceddings of the Third International Conference on System ICONS. (1): 306-311, 2008.

[9] E. B. Ferreira. As demonstrações e a formação do professor de matemática: uma contribuição dos ambientes de geometria dinâmica. Dissertação de Mestrado. Universidade Federal do Rio de Janeiro, 2006.

[10] E. B. Ferreira, A. B. Soares, C. Lima. As Demonstrações no Ensino da Geometria: discussões sobre a formação de professores através do uso de novas tecnologias. Bolema. 22(34): 185-208, 2009.

[11] E. Buchbinder. Beyond Checking: Experiences of the Validation Interview. Qualitative Social Work. 10: 106-122, 2011.

[12] F. H. Ho, Y. H. Leong. Using dynamic geometry software in teaching geometry proof. In: Proceedings of the 5th East Asia Regional Conference on Mathematics Education, 2010. Disponível em: http://hdl.handle.net/10497/4473. Acessado em: 18.07.12.

[13] G. T. Barcelos, S. C. F. Batista, P. A. Behar, L. M. Passerino. Applets em Ambientes de Geometria Dinâmica: Ações para a Formação de Professores de Matemática. Revista Novas Tecnologias na Educação - RENOTE. 7(3): 559-560, 2009.

[14] I. L. Batista, T. Nagafuchi. Um estudo históricofilosófico acerca do papel das demonstrações em cursos de bacharelado em matemática. Bolema., 23(37): 1081-1110, 2010.

[15] I. Bicudo. Demonstração em matemática. Bolema. 15(18): 79-90, 2002.

[16] I. B. C. Cortelazzo, J. P. Romanowski, R. Z. M. Ribeiro. Cursos de Graduação a distância: inclusão e qualidade. Em: Congresso Internacional da ABED, 2007. Disponível em: http://www.abed.org.br/congresso2007/tc/82200 724656PM.pdf. Acessado em: 18/07/20012.

[17] J. Ponte. Estudos de Caso em Educação Matemática. Bolema. (25): 105-132, 2006.

[18] J. W. Creswell. Qualitative Inquiry and Research Design. Sage Publications Inc, Second Edition. Thousand Oaks, CA, USA, 2007. 
[19] J. W. Willis. Foundations of Qualitative Research: interpretative and critical approaches. Sage Publications Inc, Thousand Oaks, CA, USA, 2007.

[20] J. Zhang, X. Peng, M. Chen. Practice and thinking about teaching dynamic geometry course in normal university. Electronic Journal of Mathematics and Technology. 4(2): 1-15, 2010.

[21] L. O. Brandão, S. Isotani,, J. G. Moura. Imergindo a Geometria Dinâmica em Sistemas de Educação a Distância: IGEOM e SAW. Revista Brasileira de Informática na Educação. 14(1): 41-49, 2006.

[22] M. Hohenwarter, K. Fuchs, K. Combination of Dynamic Geometry, Algebra and Calculus in the Software System GeoGebra. In: Computer Algebra Systems and Dynamic Geometry Systems in Mathematics Teaching Conference, 2004.

[23] M. Hohenwarter, J. Hohenwarter. Ways of linking geometry and algebra: the case of Geogebra. In: D. Küchemann (eds.) Proceedings of the British Society for Research into Learning Mathematics. 27(3): 126-131, 2007.

[24] M. Satterfield. Geometer's Sketchpad: Single User Package, Version 3. Mathematics, Teaching in the Middle School. 7(3): 184-194, 2001.

[25] Portal of Mathematical Collaboration. Disponível em: http://tabulae.net/pcm/. Acessado em: 18/07/2012.

[26] R. F. Carneiro, C. B. Passos. As Concepções de Professores de Matemática em Início de Carreira sobre as Contribuições da Formação Inicial para a Utilização das Tecnologias de Informação e Comunicação. Bolema. 23(36): 775-800, 2010.

[27] S. C. Santos, M. C. Borba. Internet e Softwares de Geometria Dinâmica como Atores na Produção Matemática on-line. ZETETIKÉ Unicamp. 16(29): 93-116, 2008.

[28] J. Trgalova, A. P. Jahn, S. Soury-lavergne. Quality process for dynamic geometry resources: The Intergeo project. In: V. Durant-Guerrier, S. Soury-lavergne, F. Arzarello (eds.), Proceedings of the Sixth European Conference on Research on Mathematics Education. INPR: 1161-1170, 2010

[29] U. Kortemkamp, A. M. Blessing, C. Dohrrmann, Y. Kreis, P. Libbreth, C. Mercat. Interoperable Interactive Geometry for Europe - First technological and educational results and future challengers of the Intergeo project. In: V. Durant-
Guerrier, S. Soury-Lavergne, F. Arzarello (eds.). Proceedings of the Sixth European Conference on Research on Mathematics Education. INPR: 1150-1160, 2010.

[30] J. P. Gonçalves. Reflexões sobre os processos de ensino/aprendizagem de Matemática baseados no software educativo FORMEL. Revista Brasileira de Informática na Educação. 12(2): 51-55, 2004.

[31] R. Nevado. Ambientes Virtuais que Pontencializam as Relações de Ensino-Aprendizagem. Em: Novas formas de aprender: comunidades de aprendizagem. Ministério da Educação. TV Escola. Boletim 15: 14-20, 2009.

[32] L. Z. Pedro, S. S. Borges, A. M. Z. Lopes, J. P. T. Souza, A. A. F. Brandão, L. O. Brandão, S. Isotani . Projeto e Desenvolvimento de um Aplicativo de Geometria Interativa para Dispositivos Móveis. Anais do $23^{\circ}$ Simpósio Brasileiro de Informática na Educação, 2012.

[33] S. E. Ainsworth, P.A. Bibby, D. J. Wood. Examining the effects of different multiple representational systems in learning primary mathematics. Journal of the Learning Sciences. 11(1), 2562, 2002.

[34] S. E. Ainsworth. DeFT: A conceptual framework for learning with multiple representations. Learning and Instruction, 16(3), 183-198, 2006.

[35] R. M. Bernardes, T. Z. Torres. Tecnologias Sociais, TICs e Educação: pilares para a construção da Tecnopedia Social Rural TeSoRu. Anais do XXI Simpósio Brasileiro de Informática na Educação, 2010.

[36] M.. J. G. S. Tanbellini, L. O. Brandão. O uso da Geometria Interativa como Facilitador no Ensino e Aprendizagem de Matemática: estudo com duas turmas de sexta série do ensino fundamental. Anais do XVI Workshop Sobre Informática na Escola, 2010.

[37] N. V. Labeke. Multiple External Representations in Dynamic Geometry: a Domain-Inspired Design. In: S. E. Ainsworth, R. V. Cox. R. V. (eds.), External representations in AIED: Multiple forms and multiple roles, International Journal of Artificial Intelligence in Education. (12), 1040-1049, 2010 